\title{
Commentary: Toward truth in advertising
}

John A. Elefteriades, MD, PhD (Hon), Mohammad A. Zafar, MD, and

Bulat A. Ziganshin, MD, PhD

\footnotetext{
From the Aortic Institute at Yale-New Haven Hospital, Yale University School of Medicine, New Haven, Conn Disclosures: Dr Elefteriades: Co-Founder, CoolSpine; Consultant for CryoLife; Data/Safety Monitoring Board for Terumo; Data/Safety Monitoring Board for Jarvik Heart. All other authors have nothing to disclose with regard to commercial support.

Received for publication July 5, 2019; revisions received July 5, 2019; accepted for publication July 5, 2019. Address for reprints: John A. Elefteriades, MD, PhD (Hon), Aortic Institute at Yale-New Haven Hospital, Yale University School of Medicine, Clinic Building CB 317, 789 Howard Ave, New Haven, CT 06519 (E-mail: john.elefteriades@yale.edu).

J Thorac Cardiovasc Surg 2019;158:1055-7

$0022-5223 / \$ 36.00$

Copyright (c) 2019 by The American Association for Thoracic Surgery

https://doi.org/10.1016/j.jtcvs.2019.07.053
}

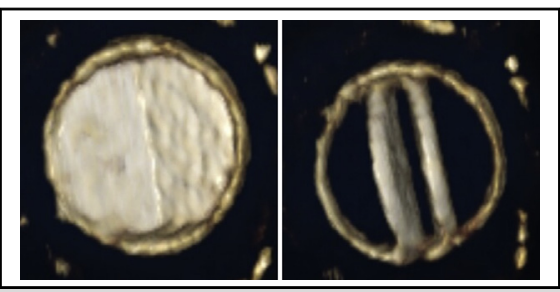

Misleading findings of PPM rectified by cine computed tomography of the aortic valve.

Central Message

Valve labeling requires quantum improvement to achieve accurate correlation with physical and performance characteristics of individual valves and to ensure consistency among major manufacturers.

See Article page 1041 .
The Valve Labelling Task Force and its initial report ${ }^{1}$ were borne out of frustration-frustration arising from the fact that labeled valve sizes seem to bear little relationship to physical characteristics of the valves themselves and do not correlate between different manufacturers. Christakis and colleagues ${ }^{2}$ from Canada called attention to this issue 2 decades ago, pointing out not only the inaccuracies in labeling but also the potential deleterious impact on patients of ad hoc on-table selection based on inaccurate size labeling. Specifically, nominal valve sizes have been found not to correlate with the actual physical dimensions of the valve, which are so important for the implanting surgeon. The Task Force was convened specifically to address these issues and to call on manufacturers to introduce geometric accuracy and cross-manufacturer uniformity in the industry. The goal of these efforts is to achieve informative, accurate, and meaningful on-the-box valve labeling. Dr Pieter Kappetein did an extraordinary job leading and moderating the discussion process.

Even the experienced valve surgeon will find in this Consensus Report valuable fundamental information about the design, construction, and biological compatibility of both biological and mechanical heart valves-interesting and important information with which they may not already be familiar. Also, the reader can gain a wealth of understanding about echocardiographic assessment of prosthetic heart valves, due in large part to the participation of Dr Pibarot, who has written extensively on these topics.

Ex vivo valve testing (in reference laboratories) can assess effective orifice area and regurgitant fraction.
In vivo assessment of these same characteristics is usually done by Doppler echocardiography. Both the ex vivo and in vivo measurements are important and relevant to valve performance. For the practicing surgeon, it is important to remember Bernoulli's law: Specifically, that the pressure drop across a valve is 4 times the velocity squared $\left(\Delta \mathrm{P}=4 \mathrm{v}^{2}\right)$.

In addition to issues of valve labeling, this Task Force document beautifully addresses certain important related phenomena about the assessment of valve adequacy and function after implantation.

\section{PRESSURE GRADIENT ESTIMATION ACROSS AORTIC PROSTHETIC VALVES}

Important for surgeons, who may receive calls about "high gradients" across either mechanical or biological prosthetic aortic valves, are 2 echocardiographic phenomena. First, the "pressure recovery" phenomenon may exaggerate the gradient across a prosthetic heart valve because blood flow velocity is commonly measured at the vena contracta (narrowest diameter of the stream) just above the valve, which is not representative of the velocity of the total flow through the aorta. Second, measurement of velocity across bileaflet mechanical valves is often done at the orifice between the leaflets, where it will be higher than in the lateral orifices. This sampling issue of measurement of velocity through the central orifice of a bileaflet mechanic valve may exaggerate the gradient. The bottom line is that because of these echocardiographic 

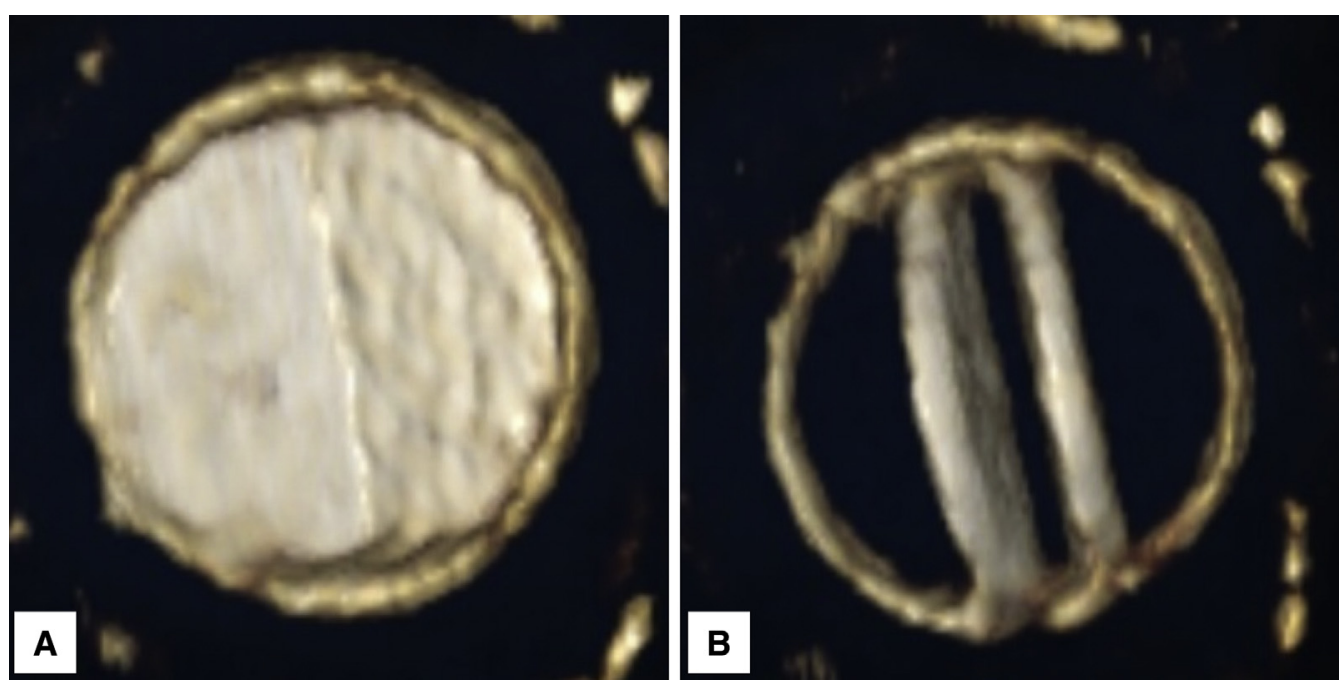

FIGURE 1. Misleading findings of PPM. Images from cine computed tomography of prosthetic valve (23 St Jude Medical, St Paul, Mo) (shown in stills in closed, A, and open, B, positions; Video 1) in a patient with a new increase in velocity (to $4.6 \mathrm{msec}$ ) and transvalvular gradient (to peak $86 \mathrm{~mm} \mathrm{Hg}$ ). The referring physician suspected valve dysfunction. However, the cine computed tomography confirms excellent valve motion. Over 13 years, the patient's weight had increased from 190 to $290 \mathrm{lbs}$ (13.8-point increase in body mass index). This weight gain required higher cardiac output and produced increased velocities and gradients across the valve. This case illustrates that weight gain must be considered as a potential cause of new PPM.

mathematical "quirks," the echocardiographic gradients after aortic valve implantation are often exaggerated, sometimes substantially so. So, your valve may not be as "bad" as the echocardiographer suggests. Such factors should be carefully considered before proceeding to replace a surgically implanted valve with putative "restenosis."

\section{PATIENT-PROSTHESIS MISMATCH}

The phenomenon of patient-prosthesis mismatch (PPM) has received considerable attention over many years, again, brought early to attention by Hanayama and colleagues. ${ }^{3,4}$ No surgeon wants a patient to experience continued obstruction to left ventricular outflow after aortic valve replacement. As Dr Tirone David has so vigorously emphasized, every surgeon should be comfortable enlarging the aortic annulus when necessary. 5,6

However, it is worth emphasizing, especially for junior surgeons, that many bad things can happen when attempting to place too large a valve in a small aortic annulus. The valve may not seat well. The coronary arteries may be compromised. The aorta may be torn. These are serious and acutely life-threatening complications.

In terms of annular enlargement, the corner of the extended aortotomy through the aortic valve annulus can be a troublesome source of bleeding. This area is difficult to expose and access in case additional hemostatic sutures are required. The annulus and adjacent aorta are often calcified in small roots needing enlargement, further jeopardizing achievement of hemostatic closure. In fact, elevated mortality after aortic annular enlargement has been demonstrated. ${ }^{7}$ The decision to enlarge the annulus raises the operation to a higher technical and operative risk plane. This decision to enlarge the annulus should be made thoughtfully, assessing benefits and risks in that individual patient.

Another factor is that PPM is recognized commonly in obese individuals. In our own study of patients with increased gradient over time, we have seen a correlation with intercurrent weight gain (Figure 1 and Video 1). ${ }^{8}$

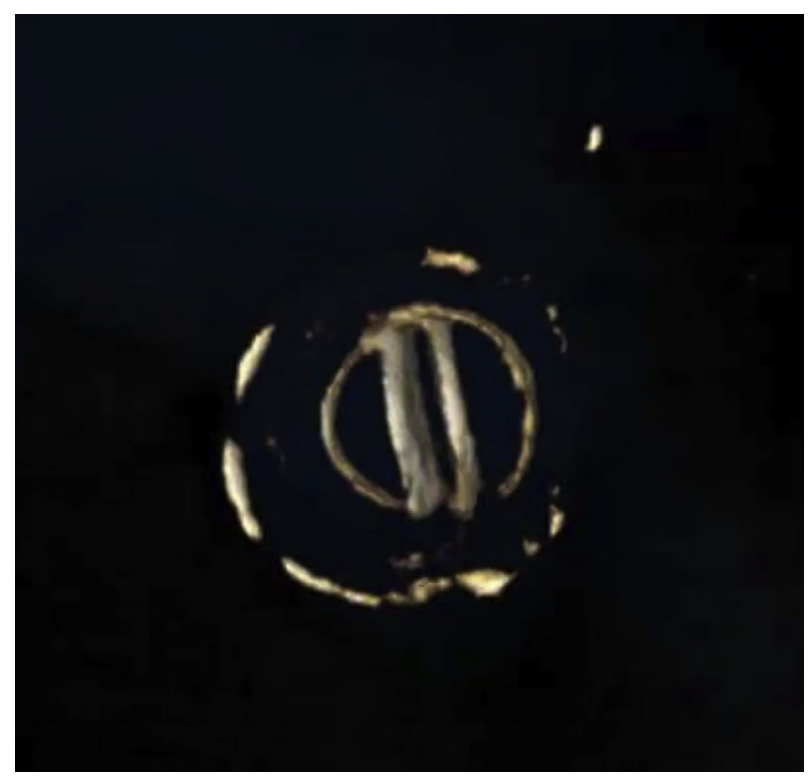

VIDEO 1. Cine computed tomography of the patient from Figure 1 demonstrating excellent leaflet motion. Video available at: https://www jtcvs.org/article/S0022-5223(19)31523-5/fulltext. 
No prosthetic valve will ever be as efficient as the patient's original biological valve. The original native biological valve and annulus are matched to the patient's lean body mass. This is the annulus we have to work with in aortic valve replacement. With age and inactivity, substantial weight gain can and often does occur. This surgeon's opinion is that we can cause more harm than good by trying to squeeze in a valve big enough to accommodate the patient's often considerable weight gain in later life. To this surgeon, it seems that the source of a higher than optimal transvalvular gradient may well be the weight gain itself, not the anatomically proportionally sized prosthetic valve. Weight gain is often the problem, and weight loss can solve the apparent PPM. Opinions vary strongly among surgeons on these points.

\section{CONCLUSIONS}

This article by the Task Force represents its first product, laying out the problem, as well as the mechanics, biology, and physiology involved. The next product is intended to be a set of specific guidelines for valve box labeling and box insert composition. This Task Force is tackling boldly and comprehensively the long-lingering issue of inaccurate and misleading valve labeling. We look forward to the upcoming recommendations for effectively rectifying this situation.

\section{References}

1. Durko AP, Head SG, Pibarot P, Atluri P, Bapat V, Cameron DE, et al Characteristics of surgical prosthetic heart valves and problems around labeling: a document from the European Association for Cardio-Thoracic Surgery (EACTS) - the Society of Thoracic Surgeons (STS)—American Association for Thoracic Surgery (AATS) valve labelling task force. J Thorac Cardiovasc Surg. 2019;158:1041-54.

2. Christakis GT, Buth KJ, Goldman BS, Fremes SE, Rao V, Cohen G, et al. Inaccurate and misleading valve sizing: a proposed standard for valve size nomenclature. Ann Thorac Surg. 1998;66:1198-203.

3. Hanayama N, Christakis GT, Mallidi HR, Rao V, Cohen G, Goldman BS, et al. Determinants of incomplete left ventricular mass regression following aortic valve replacement for aortic stenosis. J Card Surg. 2005;20:307-13.

4. Hanayama N, Christakis GT, Mallidi HR, Joyner CD, Fremes SE, Morgan CD et al. Patient prosthesis mismatch is rare after aortic valve replacement: valve size may be irrelevant. Ann Thorac Surg. 2002;73:1822-9.

5. Peterson MD, Borger MA, Feindel CM, David TE. Aortic annular enlargement during aortic valve replacement: improving results with time. Ann Thorac Surg. 2007:83:2044-9.

6. Feindel CM. Aortic root enlargement in the adult. Oper Tech Thorac Cardiovasc Surg. 2006;11:2-15.

7. Sommers KE, David TE. Aortic valve replacement with patch enlargement of the aortic annulus. Ann Thorac Surg. 1997;63:1608-12.

8. Hsu C, Bourganos K, Zafar M, et al. Cine-computed tomography for the evaluation of prosthetic heart valve function. Cardiology. 2019 [In press]. 